\title{
Kissing premolars and follow up of the eruption of the impacted premolar over 3 years: a rare case
} report

\begin{abstract}
Kissing teeth is a rare condition discovered mainly accidentally first reported by van hoof in 1973 where both teeth are in the same follicle. Whether both teeth in kissing case need surgical removal or just one. And if the remaining tooth need eruption follows up or not, it is related to each case individually. This is a report of 16 years old with kissing premolars where surgical removal of the supplemental tooth was performed and follow-up of the first premolar until its eruption. A classification is added to help describe any kissing teeth and to give an impression about the severity of the condition.
\end{abstract}

\author{
Volume 9 Issue I - 2018 \\ Jihad Mohammed Jomhawi,' Abd Albaset M \\ Odat, ${ }^{2}$ Rupak Sethuraman, ${ }^{3}$ Mohammad H Al \\ Nabulsi ${ }^{4}$ \\ 'Department of Pediatric Dentistry, Majmaah University, Saudi \\ Arabia \\ ${ }^{2}$ Department of Oral \& Maxillofacial Surgery, Jordan University \\ of Science and Technology, Jordan \\ ${ }^{3}$ Department of Oral Medicine and Radiology, Majmaah \\ University, Saudi Arabia \\ ${ }^{4}$ Department of Conservative Dentistry, Majmaah University, \\ Saudi Arabia
}

Correspondence: Jihad Mohammed Jomhawi, Department of Pediatric Dentistry, College of Dentistry, Majmaah University, Saudi Arabia, Email jjomhawi@yahoo.com

Received: December II, 2018 | Published: January 29, 2018

\section{Introduction}

The term kissing teeth refers to two teeth in the same follicle in the jaw with their crowns facing each other and the same was first described by Van Hoof. ${ }^{1}$ An analysis of radiographs of several reported cases of kissing teeth shows that both teeth in such a pattern resemble each other and develop from one tooth germ. ${ }^{1-5}$ Such a phenomenon can be seen with respect to any teeth in the dentition. This paper reports the kissing of a premolar with a supernumerary tooth and the follow up of the eruption of the impacted premolar for a period of three years after surgical removal of the supernumerary tooth.

\section{Case report}

A 16 year old female patient reported to the outpatient dental department in Princess Basma teaching hospital with a chief complaint of irregularly placed teeth. The patient was referred from a private dental clinic for the same. Medical history did not reveal any abnormality. Past dental, family and personal history was noncontributory. On general examination, the patient was moderately built and moderately nourished and her vital signs were within normal limits. Extra oral examination revealed no gross facial asymmetry or any other craniofacial abnormalities. Intra oral examination revealed that the patient had poor oral hygiene, grossly decayed lower left first permanent molar, and retained lower left first primary molar, deep pockets all over the first permanent molars, with a pocket depth of 8 $\mathrm{mm}$ for tooth number 36 mesially. Panoramic radiograph was taken which showed that all upper and lower teeth were present and tooth number 34 was impacted with its crown tilted in a distal direction with a supernumerary tooth in a kissing pattern pushing the crown of tooth number 44 distally and the root of the supernumerary tooth was directed mesially between the permanent canine and primary first molar, towards the distal cervical area of the canine forming an obtuse angle with 44 and both teeth arose from the same follicle (Figure 1). Surgical removal of the supernumerary tooth was carried out. Tooth number 36 was grossly decayed with caries extending into the furcation and also showing periapical radiolucency therefore, it was also removed. Conventional root planing was carried out for all the remaining first permanent molars. The impacted tooth was followed up in order to check for spontaneous eruption for a period of three years (Figures $2 \& 3$ ). After the completion of the waiting period, surgical exposure of the tooth was carried out and the tooth was found under the gingiva (Figure 4).

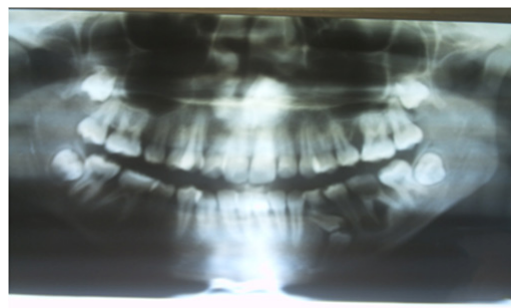

Figure I A panoramic radiograph showing kissing premolar and supernumerary in a partial pattern.

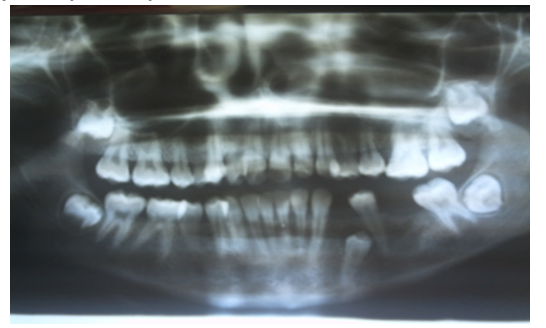

Figure 2 A panoramic radiograph showing the position of the lower first premolar 7 months after surgical removal of the supplemental tooth in kissing position. 


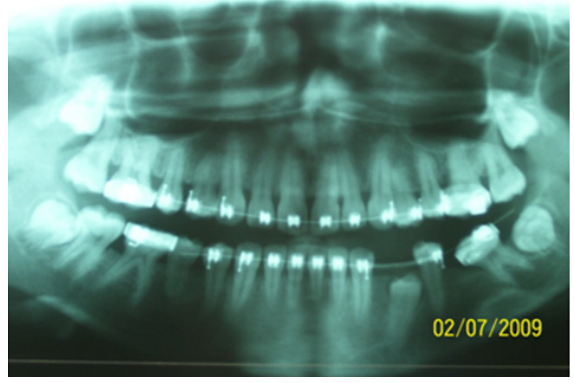

Figure $3 \mathrm{~A}$ panoramic radiograph showing the position of the lower first premolar 3 years after surgical removal of the supplemental tooth in kissing position.

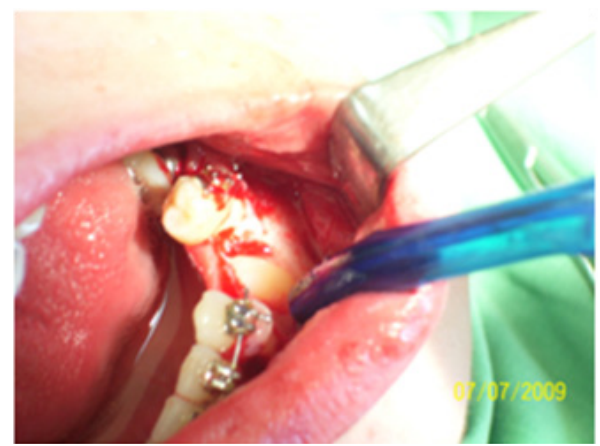

Figure $4 \mathrm{~A}$ photograph showing the lower first premolar after surgical reflection of the covering gingiva.

\section{Discussion}

Kissing is not just another examination finding, but it also deals with non- erupting of permanent teeth and thus is of more concern at a younger age. In order to give an impression about its severity a classification according to the angle of contact between the two teeth involved in kissing can be made as follows: Full kissing if both teeth facing each other are along the same long axis. Partial kissing is there is an obtuse angle between the long axis of crowns of both the teeth. Minimal kissing if the long axis of both the crowns is at an acute angle to each other. The incidence of supernumerary premolars involved in kissing varies between $0.2 \%$ and $0.64 \%{ }^{6,7}$ Management of impacted tooth after surgical removal of the supernumerary tooth ranges from assessment with periodic radiographic examination to its surgical removal. 8 Since the supernumerary tooth results in impaction of the other premolar as well as pushes it distally, it is removed surgically as in the present case. In this case, it took a period of three years for the impacted tooth to move nearly from the apex of the second premolar to the crest of alveolar bone. However, even after this period, the tooth did not erupt through the gingiva. Early diagnosis and removal of the supernumerary tooth will reduce the complications including the delay in the eruption of the permanent tooth. Eruption of the permanent tooth is related to the degree of root formation at the time of surgical removal of the supernumerary tooth and the scar formed after the operation, since the root formation was completed in this case it took the tooth nearly three years to reach the alveolar bone crest. 10 Once the supernumerary tooth is removed most of the impacted teeth erupt spontaneously, and the period of eruption could be up to three years, depending on the degree of displacement, the type of supernumerary tooth, the space in the jaw and the time of surgical removal. ${ }^{11-14}$ The present patient had localized aggressive periodontitis so the extracted tooth space was closed by orthodontic treatment. Other periodontal involved teeth showed a reduction in pocket depth up to $4 \mathrm{~mm}$ using conventional root planing and irrigating the pockets with chlorhexidine, prescription of antibiotics and patient motivation. The extent of alveolar bone destruction around the lower left second premolar after removal of the supernumerary and removal of the non restorable destroyed lower left first molar as well as the follow up after treating the periodontal condition necessitated the need to postpone orthodontic treatment.

\section{Acknowledgements}

None.

\section{Conflicts of interest}

None.

\section{References}

1. Van Hoof RF. Four kissing molars. Oral Surg Oral Med Oral Pathol. $1973 ; 35(2): 284$

2. Robinson JA, Gaffney W, Soni NN. Bilateral 'kissing' molars. Oral Surg Oral Med Oral Pathol. 1991;72(6):760.

3. Nakamura T, Miwa K, Kanda S, et al. Rosette formation of impacted molar teeth in mucopolysaccharidoses and related disorders. Dentomaxillofac Radiol. 1992;21(1):45-49.

4. McIntyre G. Kissing molars: an unexpected finding: Dent Update. 1997;24(9):373-374.

5. Buffano P, Gillesio C. Kissing molars. $J$ Craniofac Surg. 2009;20(4):1269-1270

6. Parry RR, Iyer VS. Supernumerary teeth amongst orthodontic patients in India. Br Dent J. 1961;111:257-258.

7. Rubenstein LK, Lindauer SJ, Isaacson RJ, et al. Development of supernumerary premolars in an orthodontic population. Oral Surg Oral Med Oral Pathol. 1991;1(3):392-395.

8. Juneja M. Not kissing. Br Dent J. 2008;204(11):597.

9. Becher A. General principles related to the diagnosis and treatment of impacted teeth. Orthodontic Treatment of Impacted Teeth. 1st edn. Martein Dunitz, UK. 1998:2-3.

10. Bart Witsenburg, Geert Boering. Eruption of impacted permanent upper incisors after removal of supernumerary teeth. Int J Oral Surg. 1981;10(6):423-431.

11. Hattab FN, Yassin OM, Rawashdeh MA. Supernumerary teeth: Report of three cases and review of the literature. $J$ Dent Child. 1994;61(56):382-393.

12. Zhu JF, Marcushamer M, King DL, et al. Supernumerary and congenitally absent teeth: A literature review. J Clin Pediatr Dent. 1996;20(2):87-95.

13. Bryan RA, Cole BO, Welbury RR. Retrospective analysis of factors influencing the eruption of delayed permanent incisors after supernumerary removal. Eur J Paediatr Dent. 2005;6(2):84-89.

14. Leyland L, Batra P, Wong F, et al. A retrospective evaluation of the eruption of impacted ermanent incisors after extraction of supernumerary teeth. J Clin Pediatr Dent. 2006;30(3):225-231. 